\title{
Multidose Risperidone Treatment Evaluated in a Rodent Model of Tardive Dyskinesia
}

\author{
Xue-Min Gao*,', Thomas Cooper ${ }^{2}$, Raymond F Suckow² and Carol A Tamminga' \\ 'Department of Psychiatry, The University of Texas Southwestern Medical Center at Dallas, Dallas, TX, USA; ${ }^{2}$ Department \\ of Psychopharmocology, Nathan Kline Research Institute, Orangeburg, NY, USA
}

\begin{abstract}
Risperidone is a second-generation antipsychotic that lacks acute motor side effects at low doses ( $<6 \mathrm{mg} /$ day), but above this level is associated with parkinsonism and akathesia. The literature suggests an association between acute motor side effects and tardive dyskinesia (TD); therefore, we hypothesized that low dose levels of risperidone will spare TD. As clinical studies of TD liability with fixed doses of risperidone are difficult to conduct, we tested low and high doses of risperidone in a rodent model of TD, vacuous chewing movements (VCMs) production. Low doses of risperidone $(1.5 \mathrm{mg} / \mathrm{kg} /$ day) resulted in control levels of VCMs after 6 months of treatment, whereas high doses of risperidone $(6 \mathrm{mg} / \mathrm{kg} / \mathrm{day})$ produced VCM in the same range as haloperidol. Plasma drug levels are reported. If this animal model predicts TD risk in humans, the TD liability with low-dose risperidone is at a placebo level, whereas higher doses show haloperidol-like TD risk, as predicted from the acute motor effects.
\end{abstract}

Neuropsychopharmacology (2006) 3 I, I 864-1868. doi:I 0. I 038/sj.npp. I 300975; published online 23 November 2005

Keywords: antipsychotic; haloperidol; tardive dyskinesis; vacuous chewing movement; 5HT2A receptor

\section{INTRODUCTION}

Risperidone is a benzisoxazole derivative belonging to the second generation of antipsychotic drugs (Janssen et al, 1988; Leysen et al, 1994). It and its major active metabolite 9-OH-risperidone are effective antipsychotics compared to placebo and to other first- and second-generation antipsychotic drugs (Conley and Mahmoud, 2001; Marder and Meibach, 1994). Furthermore, it has an acceptable side effect profile in humans, particularly at low doses (Marder and Meibach, 1994). One of the distinctive characteristics of this drug is that its motor side effect profile (parkinsonism and akathesia) is low at doses less than $6 \mathrm{mg} /$ day, but emerges at higher doses. Clinically, the antipsychotic dose range of risperidone is $2-16 \mathrm{mg}$ daily, whereas the acute motor side effect dose range generally begins in adults above $6 \mathrm{mg}$ and increases in a linear fashion with higher doses (Marder and Meibach, 1994). Above the daily dose of $8 \mathrm{mg}$, little motor side effect advantage accrues to risperidone compared to haloperidol, because risperidone shows haloperidol-like extrapyramidal motor effect.

\footnotetext{
*Correspondence: Dr X-M Gao, Department of Psychiatry, The University of Texas Southwestern Medical Center at Dallas, 5323 Harry Hines Blvd., Dallas, TX 75390-9070, USA, Tel: + I 214648 5I40, Fax: + I 2146484948 ,

E-mail: Xue-Min.Gao@UTSouthwestern.edu

Received 12 May 2005; revised and accepted 10 October 2005

Online publication: 20 October 2005 at http://www.acnp.org/citations/ Npp 1019050503 I5/default.pdf
}

Risperidone doses in the range of $2-6 \mathrm{mg} /$ day induce little parkinsonian motor side effects or akathesia in clinical use. It has remained a clinical question whether risperidone doses at or below $6 \mathrm{mg} /$ day are also minimal risk for tardive dyskinesia (TD). The idea that acute motor side affects predict eventual TD received support when Kane and colleagues (Kane and Smith, 1982; Kane et al, 1986) showed that acute EPS is a risk factor for TD. In addition, several chronic antipsychotic treatment studies have shown a decrease in TD risk with second-generation antipsychotic use, including studies examining risperidone (Correll et al, 2004) and risperidone use in the susceptible elderly (Jeste et al, 1999). Moreover, risperidone in humans has been observed to have an antidyskinetic effect at doses above $6 \mathrm{mg}$, but not below (Chouinard et al, 1993), consistent with the sparing of hypokinetic (as well as later hyperkinetic) motor effects below $6 \mathrm{mg}$. Prospective studies showing differential risk between antipsychotics for TD in humans with fixed doses of risperidone would be long and arduous.

Thus, for preliminary screening, we have used a rat model of TD, chronic antipsychotic-induced vacuous chewing movement (VCM), to test the idea that low doses of risperidone will fail to induce VCMs, but that high risperidone doses will produce the TD-like syndrome. Already Marchese et al (2004) have examined subacute risperidone treatment in laboratory rats to show a reduced withdrawal VCM liability at low doses of drug.

Laboratory rats chronically treated with the traditional antipsychotic drug haloperidol or other similar drugs 
gradually develop VCMs over a time course of 3-6 months (Clow et al, 1980a,b,c; Ellison et al, 1987; Glenthoj and Hemmingsen, 1989; Gao et al, 1998; Andreassen et al, 2003). Several characteristics of these movements, including aspects of their phenomenology, etiology, and pharmacology, resemble TD in humans (Tamminga et al, 1990; Waddington, 1990). This model is consistent with published criteria for evaluating animal models (McKinney and Bunney, 1969; Weiss and Kilts, 1995). Therefore, we have used this model in animals to putatively predict the potential of risperidone to generate TD (Gao et al, 1997; Gao et al, 1998). In this model, neither clozapine, olanzapine, or sertindole are associated with the VCMs, while haloperidol induces these movements across a wide dose range (Tamminga and Woerner, 2002). We have selected doses in animals that produce blood levels within the range of human antipsychotic response. We have dosed laboratory rats using two doses of risperidone over 6 months and compared the development of VCMs to haloperidol and a control condition. The two dose ranges of risperidone were designed to be comparable to human doses of low and high risperidone, matching low and high plasma drug levels across the animal and clinical studies in the human therapeutic dose range.

\section{METHODS}

\section{Animals}

Male Sprague-Dawley rats were divided into four treatment groups: (1) water ad libitum $N=10$; (2) haloperidol, $1.5 \mathrm{mg} /$ $\mathrm{kg} /$ day, $N=10$; (3) risperidone $1.5 \mathrm{mg} / \mathrm{kg} /$ day, $N=12$; (4) risperidone $6 \mathrm{mg} / \mathrm{kg} / \mathrm{day}, N=13$. Rats were housed in regulated animal quarters, fed ad libitum, and kept on $12 \mathrm{~h}$ light/dark cycle. Dosing began when the animals were $200-220$ g or approximately $6-8$ weeks old.

\section{Drug Administration}

The rats were given drinking water containing either no drug, haloperidol, or risperidone (2 concentrations). Haloperidol was dissolved in $10 \%$ of glacial acetic acid. The solution was diluted with distilled water and the $\mathrm{pH}$ was adjusted to 5.5-6.0, using $10 \mathrm{~N}$ sodium hydroxide to produce a stock solution of $0.25 \mathrm{mg} / \mathrm{ml}$. This stock solution was further diluted with distilled water to $0.025 \mathrm{mg} / \mathrm{ml}$ and provided as drinking water for 7 days. The test drug, risperidone, was dissolved in a minimum volume of glacial acetic acid. That solution was diluted with distilled water and adjusted to $\mathrm{pH} 5.5-6.0$ using $10 \mathrm{~N}$ sodium hydroxide to give a stock solution of $0.33 \mathrm{mg} / \mathrm{ml}$. This stock was used at a $0.1 \mathrm{mg} / \mathrm{ml}$ solution for high dose and was diluted to $0.025 \mathrm{mg} / \mathrm{ml}$ solution for the low dose every 7 days. These neuroleptic solutions were administered in the drinking water continuously for 6 months. The dose of antipsychotic drug in the drinking water was modified weekly according to the measured daily water intake of the rats to produce the state dose per group.

Trunk blood was collected at the time of killing and the plasma was frozen at $-20^{\circ} \mathrm{C}$ until analysis. Haloperidol and reduced haloperidol were quantified using a modification of the GC/NPD method of (Bianchetti and Morselli, 1978) with chlorohaloperidol as the internal standard. Risperidone and 9-OH-risperidone plasma levels were analyzed using a modification of the liquid chromatographic procedure of Woestenborghs et al (1992). The two major changes were in the extraction procedure from plasma, and the liquid chromatographic column employed. The limit of detection is $2.5 \mathrm{ng} / \mathrm{ml}$ for each component. Interassay variability for risperidone and 9-OH-risperidone for the high-, medium-, and low-quality controls is less than $8.6 \%(n=34$ days). These assays were performed in the laboratory at the Nathan Kline Institute.

\section{Assessment of VCMs}

Individual rats were observed in a small Plexiglas cage $(30 \times 18 \times 25 \mathrm{~cm})$ that was completely empty of contents, including bedding. Rats were allowed up to $5 \mathrm{~min}$ to adapt to the cage before rating. Then, the numbers of VCMs were counted for $5 \mathrm{~min}$ by two experienced raters blind to the drug status of rats. The two ratings were averaged for the final score. VCM ratings were carried out at baseline and monthly thereafter for each drug group. Two ratings sessions were done at the end of the last treatment month and averaged for the 6-month end-treatment rating. Where these two final ratings differed by more than $15 \%$, a third rating was done and the three averaged for the final score.

Rat VCMs were analyzed two ways: (1) by a simple average of rat dyskinesia scores across treatment groups; (2) by a dichotomy into dyskinetic and nondyskinetic (or severe and not severe) 'diagnosis,' where a score of $>8$ VCMs/5 min, identified animals as dyskinetic and lower scores, as nondyskinetic.

\section{Statistics}

A one-way analysis of variance (ANOVA) was performed to test for effect of drug on number of VCMs. A Dunnett's post hoc test, at a $p=0.05$ significance level, was performed to compare drug treatments to control.

\section{RESULTS}

Rates of VCMs in the last 2 weeks of a 6-month treatment period showed that drug treatment had a significant effect on the number of VCMs $\left(\mathrm{F}_{(3,41)}=7.51, p<0.0004\right)$. Haloperidol treatment significantly increased the chewing movements almost five-fold after this extended treatment $(p<0.05)$ (Table 1). Moreover, the percent of the rats expressing 'severe' chewing movements ( $>8 \mathrm{VCMs} / 5 \mathrm{~min}$ ) was high in the haloperidol group, $70 \%$. These results with haloperidol are consistent with VCM rates and incidence in our previously published studies (Hashimoto et al, 1998; Shirakawa and Tamminga, 1994).

Risperidone, when administered at the lower dose (designed to be analogous to a $<6 \mathrm{mg} /$ day human dose), did not produce an increase in the rate of VCMs (Figure 1) nor any change from control in the percent of 'severe' movements (Table 1). However, when risperidone was administered at the higher dose, VCM rates were significantly increased to the same range as the rates with haloperidol $(p<0.05)$ (Figure 1). Moreover, here there was 
Table I VCMs and Drug Plasma Level: Haloperidol and Risperidone

\begin{tabular}{|c|c|c|c|c|}
\hline $\begin{array}{c}\text { Drug } \\
\text { (mg/kg/24 h) }\end{array}$ & $\begin{array}{l}\text { VCMs } \\
\text { (VCMs/ } \\
5 \mathrm{~min})\end{array}$ & $\begin{array}{c}\text { \% with high } \\
\text { VCMs } \\
\text { (VCMs }> \\
8 / 5 \text { min) }\end{array}$ & $\begin{array}{c}\text { Drug } \\
\text { plasma } \\
\text { levels } \\
(X \pm S D) \\
(n g / m l)\end{array}$ & $\begin{array}{c}\text { Human } \\
\text { therapeutic } \\
\text { plasma levels } \\
(\mathrm{ng} / \mathrm{ml})\end{array}$ \\
\hline $\begin{array}{l}\text { Control } \\
(N=10)\end{array}$ & $2.75 \pm 5.1$ & 10 & - & - \\
\hline $\begin{array}{l}\text { Haloperidol } \\
1.5(N=10)\end{array}$ & $11.28 \pm 7.9^{*}$ & 70 & $3.3 \pm 2.0$ & $(4-16)$ \\
\hline $\begin{array}{l}\text { Risperidone } \\
1.5(N=12)\end{array}$ & $2.3 \pm 2.4$ & 8 & $6.2 \pm 3.2$ & $(2-12)$ \\
\hline $\begin{array}{l}\text { Risperidone } \\
6.0(N=13)\end{array}$ & $11.4 \pm 7.8^{*}$ & 54 & $47.8 \pm 9.7$ & (3-230) \\
\hline
\end{tabular}

Mean \pm SD

*P $<0.05$ vs control (Dunnett's post hoc test).

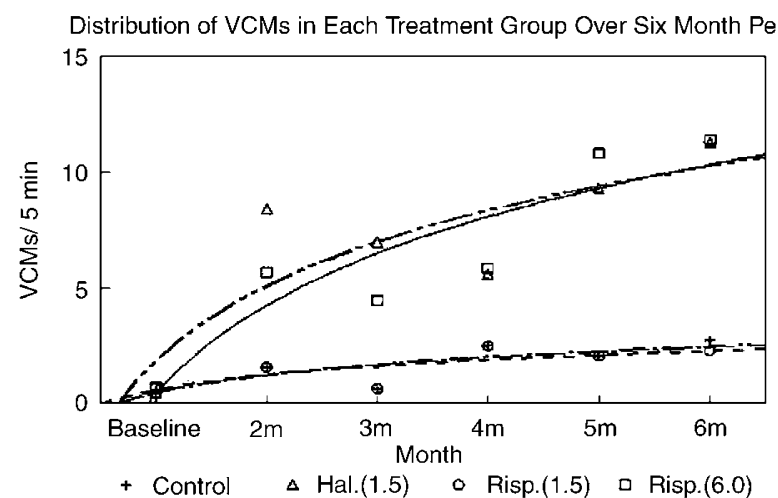

Figure I Average number of vacuous chewing movements (VCMs) for each chronic treatement group in a 5 min period measured once a month (Control: (+) (-- ); Haloperidol: $(\triangle)(---), \quad 1.5 \mathrm{mg} / \mathrm{kg} / \mathrm{day} ;$ Risperidone: $(\bigcirc)(---), 1.5 \mathrm{mg} / \mathrm{kg} /$ day; Risperidone: $(\square)(-), 6.0 \mathrm{mg} /$ $\mathrm{kg} / \mathrm{day}$ ) for a duration of 6 months.

also an increase in the proportion of animals with 'severe' movements, similar to that seen with haloperidol (Table 1). The distribution of VCMs in each treatment group over 6 month period indicated that a lower dose of risperidone has lower incidences of VCMs than higher doses of risperidone (Figure 1).

Plasma levels of haloperidol assessed in this study at the termination of treatment ( 6 months) was $3.3 \pm 2.0 \mathrm{mg} / \mathrm{ml}$. This level is within the low end of our usual assessed levels (average of $6.8 \pm 1.1 \mathrm{mg} / \mathrm{ml}$ ), but is still on the low side of the clinical therapeutic plasma level range. However, even with this low haloperidol plasma range, the VCM incidence and rate are typical. With risperidone, the metabolism of primary drug to 9-OH-risperidone is even faster than in humans; thus, most of the risperidone is in the form of the 9-OH-risperidone metabolite (Megens et al, 1994). Summing the level of primary drug with the level of metabolite in these rats (as is typically done in humans), the low- and high-dose groups show distinctly different plasma levels $(6.1 \pm 3.1$ and $47.8 \pm 1.5 \mathrm{ng} / \mathrm{ml}$, respectively) and those that fall into two ends of the very broad human therapeutic range for risperidone (Table 1).

\section{DISCUSSION}

In this experiment we show that, whereas haloperidol produces oral chewing movements with chronic treatment, chronic risperidone at the low dose fails to produce VCMs in rats while a higher risperidone dose produces classic 'involuntary' oral movements. This chronic treatment paradigm in rats is used here as a putative predictive animal model for TD liability. Several lines of evidence support the use of this animal preparation as a surrogate for TD (Glenthoj and Hemmingsen, 1989; Gunne et al, 1982; Tamminga et al, 1990; Waddington, 1990; Andreassen et al, 2003), including the observations that drugs which are associated with significant TD in humans all produce VCMs in rats, while drugs which fail to produce TD also fail to produce VCMs outside the placebo range (Ellison et al, 1987; Gunne et al, 1986). Hence, these data suggest that higher doses of risperidone ( $>6 \mathrm{mg} /$ day) may have liability for generating TD, similar to haloperidol, but low doses may well lack this liability. These results were predicted based on the human studies which consistently show that high but not low risperidone doses produce acute motor side affects (parkinsonism and akathesia) and that the incidence of acute motor side effects appear to determine TD vulnerability.

For these results to be treatment relevant, rat VCMs need to reliably model TD, not parkinsonism. In this experiment, as in our other studies, and studies from other laboratories, these movements have a slow onset, as would be expected for TD, not an immediate onset as in parkinsonism. Characteristically, the movements have a slow rate of reduction after drug discontinuation, as observed in our initial experiments (Tamminga et al, 1990), a jerky and irregular character, and do not show a regular tremor. Since these animals were killed at study end, we cannot specifically document movement reduction after drug discontinuation, but have no reason to believe it would be different than our original observation. Moreover, the movement quality in these animals was jerky and irregular, not a regular tremor. We and others (Gunne et al, 1982; Ikeda et al, 1999; Tamminga et al, 1990; Trevitt et al, 1999) have argued for a connection between these VCMs and TD, and have suggested and tested a systems pathophysiology distinct from parkinsonism to account for the movements (Shirakawa and Tamminga, 1994; Sakai et al, 2001).

Risperidone occupies the serotonin, $5 \mathrm{HT}_{2 \mathrm{~A}}$ receptor with high affinity in animal ex vivo binding studies and in human in vitro affinity studies (Leysen et al, 1993). Its dopamine, $\mathrm{DA}_{2}$ affinity is high as well, but 20 times less than the $5 \mathrm{HT}_{2}$ affinity. The rest of risperidone affinities include low but measurable occupancy at the $\mathrm{D}_{3}, \mathrm{D}_{4}, \mathrm{H}_{1}, \alpha_{1}$, and the $\alpha_{2}$ receptors. In animals, risperidone blocks serotonin- as well as dopamine (DA)-mediated pharmacologic effects in vitro and in vivo. In the human at a $6 \mathrm{mg} /$ day dose, risperidone occupies $78-88 \%$ of $5 \mathrm{TH}_{2 \mathrm{~A}}$ receptors and $75-80 \%$ of $\mathrm{DA}_{2}$ receptors (Farde et al, 1988). Again, in humans using 2, 4, and $6 \mathrm{mg}$, there is a linear dose occupancy of the $\mathrm{DA}_{2}$ receptors of 66,73 , and $79 \%$, respectively (Kapur et al, 1995). Whereas, $\mathrm{DA}_{2}$ receptor occupancy was not measured in these animals (Kapur et al, 2003), the dosing was designed to have the $24 \mathrm{~h}$ plasma levels match clinical therapeutic levels at low and high doses, with drug 
delivered continuously. Risperidone shows an 'atypical' antipsychotic profile in that it increases fos-like immediate early gene activity in the ventral, but not in the dorsal striatum in rat (Robertson et al, 1994). This potent antiserotonin action of risperidone is often invoked to explain its reduced motor side effect profile in light of its relatively high DA receptor occupancy (Leysen et al, 1994). Whether this may also influence the development of TD is a matter of speculation.

Risperidone is now widely used for the treatment of psychosis in schizophrenia and in other psychotic disorders with considerable success, especially in the elderly (Correll et al, 2004; Jeste et al, 1999). Clinical descriptions suggest that symptom reduction is broader than with first-generation compounds, extending to cognitive and affective areas and is clearly 'atypical' with respect to motor side effects particularly in the lower dose range. Naturalistic physician 'usage' studies in psychosis show that psychiatrists tend to prescribe risperidone in a biphasic fashion, with one dose peak in the low dose range of $2-4 \mathrm{mg} /$ day and the other in the high $8-12 \mathrm{mg} /$ day range(Conley and Mahmoud, 2001). Risperidone is often combined with other active antipsychotic compounds into a treatment 'cocktail,' but this is done without a solid theoretical rationale and no predictions about ultimate TD liability. Use in the elderly is typically at low doses. These data suggest that the low dose use of risperidone may not be associated with elevated TD liability. Further clinical observations are needed to test this conclusion.

\section{ACKNOWLEDGEMENTS}

Kristin Frey performed statistical analysis and Angela White participated in the animal assessments. Bulk risperidone was contributed without charge for the 6 months of dosing by Janssen Pharmaceuticals, Beerse, Belgium. This study was supported by NIMH grant (MH 37073).

\section{REFERENCES}

Andreassen OA, Ferrante RJ, Aamo TO, Beal MF, Jorgensen HA (2003). Oral dyskinesias and histopathological alterations in substantia nigra after long-term haloperidol treatment of old rats. Neuroscience 122: 717-725.

Bianchetti G, Morselli PI (1978). Rapid and sensitive method for determination of haloperidol in human samples using nitrogenphosphorous selection detection. J Chromatogr 153: 203-210.

Chouinard G, Jones B, Remington G, Bloom D, Addington D, MacEwan GW et al (1993). A Canadian multicenter placebocontrolled study of fixed doses of risperidone and haloperidol in the treatment of chronic schizophrenic patients [published erratum appears in J Clin Psychopharmacol 1993 Apr; 13(2):149] [see comments]. J Clin Psychopharmacol 13: 25-40.

Clow A, Jenner P, Theodorou A, Marsden CD (1980a). Changes in cerebral dopamine metabolism and receptors during one-year neuroleptic administration and subsequent withdrawal: relevance to brain biochemistry in schizophrenia (Review). $A d v$ Biochem Psychopharmacol 24: 53-55.

Clow A, Theodorou A, Jenner P, Marsden CD (1980b). Cerebral dopamine function in rats following withdrawal from one year of continuous neuroleptic administration. Eur J Pharmacol 63: $145-157$.
Clow A, Theodorou A, Jenner P, Marsden CD (1980c). Changes in cerebral dopamine function induced by a year's administration of trifluoperazine or thioridazine and their subsequent withdrawal. Adv Biochem Psychopharmacol 24: $335-340$.

Conley RR, Mahmoud R (2001). A randomized double-blind study of risperidone and olanzapine in the treatment of schizophrenia or schizoaffective disorder. Am J Psychiatry 158: 765-774.

Correll CU, Leucht S, Kane JM (2004). Lower risk for tardive dyskinesia associated with second-generation antipsychotics: a systematic review of 1-year studies. Am J Psychiatry 161: 414-425.

Ellison G, See R, Levin E, Kinney J (1987). Tremorous mouth movements in rats administered chronic neuroleptics. Psychopharmacology 92: 122-126.

Farde L, Wiesel FA, Halldin C, Sedvall G (1988). Central D2dopamine receptor occupancy in schizophrenic patients treated with antipsychotic drugs. Arch Gen Psychiatry 45: 71-76.

Gao XM, Hashimoto T, Cooper TB, Tamminga CA (1997). The dose-response characteristics of rat oral dyskinesias with chronic haloperidol or clozapine administration. J Neural Transm 104: 97-104.

Gao XM, Sakai K, Tamminga CA (1998). Chronic olanzapine or sertindole treatment results in reduced oral chewing movements in rats compared to haloperidol. Neuropsychopharmacology 19: 428-433.

Glenthoj B, Hemmingsen R (1989). Intermittent neuroleptic treatment induces long-lasting abnormal mouthing in the rat. Eur J Pharmacol 164: 393-396.

Gunne LM, Andersson U, Bondesson U, Johansson P (1986). Spontaneous chewing movements in rats during acute and chronic antipsychotic drug administration. Pharmacol Biochem Behav 25: 897-901.

Gunne LM, Growdon J, Glaeser B (1982). Oral dyskinesia in rats following brain lesions and neuroleptic drug administration. Psychopharmacology 77: 134-139.

Hashimoto T, Ross DE, Gao XM, Medoff DR, Tamminga CA (1998). Mixture in the distribution of haloperidol-induced oral dyskinesias in the rat supports an animal model of tardive dyskinesia. Psychopharmacology (Berl) 137: 107-112.

Ikeda H, Adachi K, Hasegawa M, Sato M, Hirose N, Koshikawa N et al (1999). Effects of chronic haloperidol and clozapine on vacuous chewing and dopamine-mediated jaw movements in rats: evaluation of a revised animal model of tardive dyskinesia. J Neural Transm 106: 1205-1216.

Janssen PA, Niemegeers CJ, Awouters F, Schellekens KH, Megens AA, Meert TF (1988). Pharmacology of risperidone ( $\mathrm{R}$ 64766), a new antipsychotic with serotonin-S2 and dopamine-D2 antagonistic properties. J Pharmacol Exp Therapeut 244: 685-693.

Jeste DV, Lacro JP, Bailey A, Rockwell E, Harris MJ, Caligiuri MP (1999). Lower incidence of tardive dyskinesia with risperidone compared with haloperidol in older patients. J Am Geriatr Soc 47: 716-719.

Kane JM, Smith JM (1982). Tardive dyskinesia: prevalence and risk factors 1959-1979. Arch Gen Psychiatry 39: 473-481.

Kane JM, Woerner M, Borenstein M, Wegner J, Liberman J (1986). Integrating incidence and prevalence of tardive dyskinesia. Psychopharmacol Bull 22: 254-258.

Kapur S, Remington G, Zipursky RB, Wilson AA, Houle S (1995). Dopamine receptor occupancy of risperidone and its relationship to extrapyramidal symptoms: a PET study. Life Sci 57: PL103-PL107.

Kapur S, VanderSpek SC, Brownlee BA, Nobrega JN (2003). Antipsychotic dosing in preclinical models is often unrepresentative of the clinical condition: a suggested solution based on in vivo occupancy. J Pharmacol Exp Ther 305: 625-631. 
Leysen JE, Janssen PM, Megens AA, Schotte A (1994). Risperidone: a novel antipsychotic with balanced serotonin-dopamine antagonism, receptor occupancy profile, and pharmacologic activity. J Clin Psychiatry 55(Suppl): 5-12.

Leysen JE, Janssen PMF, Schotte A, Luyten WHML, Megens AAHP (1993). Interaction of antipsychotic drugs with neurotransmitter receptor sites in vitro and in vivo in relation to pharmacological and clinical effects: role of $5 \mathrm{HT}_{2}$ receptors. Psychopharmacology 112: S40-S54.

Marchese G, Bartholini F, Casu MA, Ruiu S, Casti P, Congeddu E et al (2004). Haloperidol versus risperidone on rat 'early onset' vacuous chewing. Behav Brain Res 149: 9-16.

Marder SR, Meibach RC (1994). Risperidone in the treatment of schizophrenia. Am J Psychiatry 151: 825-835.

McKinney WT, Bunney WE (1969). Animal models of depression. Arch Gen Psychiatry 21: 240-248.

Megens AA, Awouters F, Schotte A, Meert TF, Dugovic C, Niemegeers CJ et al (1994). Survey on the pharmacodynamics of the new antipsychotic risperidone. Psychopharmacology 114: 9-23.

Robertson GS, Matsumura H, Fibiger HC (1994). Induction patterns of Fos-like immunoreactivity in the forebrain as predictors of atypical antipsychotic activity. J Pharmacol Exp Therapeut 271: 1058-1066.

Sakai K, Gao XM, Tamminga CA (2001). Scopolamine fails to diminish chronic haloperidol-induced purposeless chewing in rats. Psychopharmacology (Berl) 153: 191-195.
Shirakawa O, Tamminga CA (1994). Basal ganglia GABAA and dopamine D1 binding site correlates of haloperidol-induced oral dyskinesias in rat. Exp Neurol 127: 62-69.

Tamminga C, Woerner MG (2002). Clinical course and cellular pathology of tardive dyskinesia. In: Davis KL, Charney DS, Coyle JT, Nemeroff CB (eds). Neuropsychopharmacology: The Fifth Generation of Progress. American College of Neuropsychopharmacology. Lippincott Williams \& Wilkins: Philadelphia. pp 1832-1842.

Tamminga CA, Dale JM, Goodman L, Kaneda H, Kaneda N (1990). Neuroleptic-induced vacuous chewing movements as an animal model of tardive dyskinesia: a study in three rat strains. Psychopharmacology 102: 474-478.

Trevitt JT, Carlson BB, Salamone JD (1999). Behavioral assessment of atypical antipsychotics in rats: studies of the effects of olanzapine (Zyprexa). Psychopharmacology (Berl) 145: 309-316.

Waddington JL (1990). Spontaneous orofacial movements induced in rodents by very long-term neuroleptic drug administration: phenomenology, pathophysiology and putative relationship to tardive dyskinesia. Psychopharmacology 101: 431-447.

Weiss JM, Kilts CD (1995). Animal models of depression and schizophrenia. In: Schatzberg AF, Nemeroff CV (eds). Textbook of Psychopharmacology. American Psychiatric Press: Washington, DC. pp 81-123.

Woestenborghs R, Lorreyne W, Van Rompaey F, Heykants J (1992). Determination of risperidone and 9-hydroxyrisperidone in plasma, urine and animal tissues by high-performance liquid chromatography. J Chromatogr 583: 223-230. 